\title{
Investigation of kinetics of supercritical drying of alginate alcogel particles
}

\author{
İbrahim Şahin ${ }^{\mathrm{a}}$, Erdal Uzunlar ${ }^{\mathrm{b}}$, Can Erkey ${ }^{\mathrm{a}, *}$ \\ ${ }^{a}$ Department of Chemical and Biological Engineering, Koç University, Rumelifeneri Yolu, Sartyer, 34450 İstanbul, Turkey \\ ${ }^{\mathrm{b}}$ Department of Chemical Engineering, Izmir Institute of Technology, Gülbahçe Mah., Urla, 35430 İzmir, Turkey
}

G R A P H I C A L A B S T R A C T

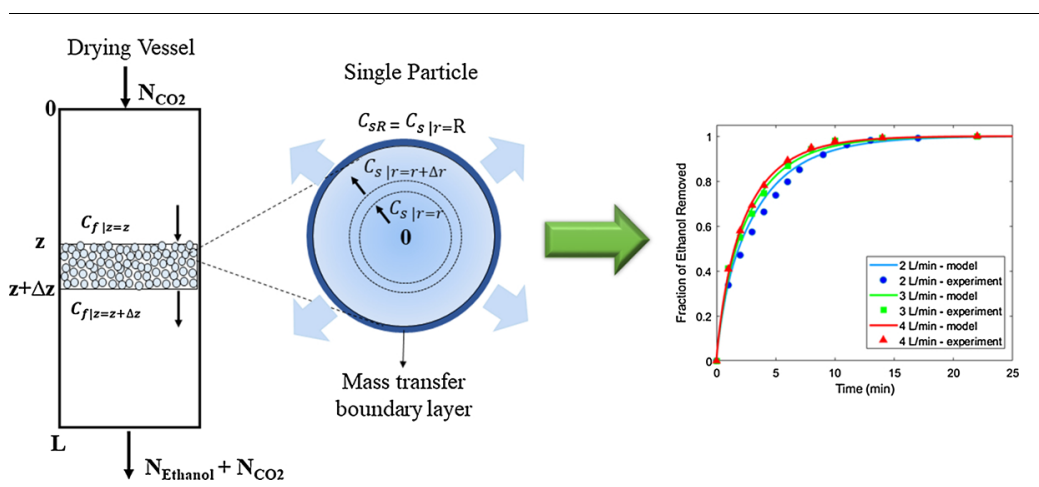

\section{A R T I C L E I N F O}

\section{Keywords:}

Aerogel

Supercritical drying

Kinetics

Mass transfer

Modeling

Calcium alginate

Mathematical model

\begin{abstract}
A B S T R A C T
Spherical calcium alginate gel particles were synthesized by dripping method. The effects of temperature, pressure, particle size and $\mathrm{CO}_{2}$ flow rate on kinetics of supercritical drying of alginate gel particles in a packed bed were investigated. Increase in $\mathrm{CO}_{2}$ flow rate, increase in temperature and decrease in particle size increased the drying rate and decreased the drying time. A mathematical model based on (i) the diffusion of the solvent inside the pores of gel particles, (ii) external mass transfer of the solvent from the surface of the gel particles into the flowing fluid stream, and (iii) convection and axial dispersion of the solvent in the flowing fluid stream was developed. A correlation for predicting external mass transfer coefficients for supercritical drying of alcogel particles was developed by fitting the model to experimental data. A good agreement between the experimental data and model results was achieved using the developed correlation.
\end{abstract}

\section{Introduction}

Aerogels have unique properties such as low density, high porosity, large surface area, and exhibit three dimensional open pore structures [1]. Aerogels were first synthesized by Kistler in 1932 [2] and since then substantial research efforts were exhausted in many research laboratories to replace glass windows with transparent silica aerogels for energy saving purposes utilizing the very low thermal conductivities of aerogels [3-6]. However, poor mechanical properties and high production costs of silica aerogel panels hindered their commercialization. Aspen Aerogels developed a composite aerogel blanket by infusing glass fibers with silica aerogel and started production of these blankets on an industrial scale in 2007 [7]. This accelerated the research on development of aerogels for use in numerous applications such as drug delivery, catalysis, tissue engineering, energy storage, adsorption, sensing, and cosmetics [8-14]. These applications generally require aerogels in the form of particles. For instance, Dow Corning produces silica silylate aerogel fine particles as thickening agents for

\footnotetext{
* Corresponding author.

E-mail address: cerkey@ku.edu.tr (C. Erkey).
} 
organic oils in personal care applications [15].

Synthesis of aerogels can generally be divided into two primary steps. The first step is forming a gel which consists of a three-dimensional network of cross-linked polymers and a solvent filling up the pore volume around the polymeric chains. In the second step, the solvent present in the pores of the gel is replaced with air in order to obtain an aerogel. The formation of vapor-liquid interface should be prevented during solvent removal since it leads to capillary stresses which collapse the pores and shrink the gel. Thus, supercritical drying is commonly used instead of ambient drying to remove the solvent from the wet-gel. In supercritical drying, a supercritical fluid, generally supercritical $\mathrm{CO}_{2}$ $\left(\mathrm{scCO}_{2}\right)$, is continuously passed over gel particles in a packed bed. During this process, solvent inside the pores of the gel particles diffuses to the surface of the gel particles and is subsequently transported by convective mass transfer from the surface into the flowing fluid stream in which convection and axial dispersion of the solvent take place. $\mathrm{CO}_{2}$ is also transported by convective mass transfer to the surface of the gel particles and by diffusion into the gel particles. At the end of supercritical drying, all of the solvent inside the pores is replaced by $\mathrm{scCO}_{2}$. After depressurization and exposure to air, $\mathrm{CO}_{2}$ inside the pores is replaced by air resulting in an aerogel. Supercritical drying is generally considered a slow process due to the slow rates of diffusion of solvent inside the pores of the gel particles. Consequently, the operational costs associated with pumping and compression of $\mathrm{CO}_{2}$ which are proportional to total amount of $\mathrm{CO}_{2}$ to completely dry the wet-gel contribute significantly to production costs of aerogels. Therefore, a fundamental understanding of kinetics of supercritical drying of gel particles is crucial for material development, scale-up and optimization of manufacturing of aerogel particles.

Until recently, the diffusion of the solvent inside the gel was considered as the only mode of mass transport in most of the studies on supercritical drying of monolithic silica alcogels [16-21]. Experimental studies showed that drying time increased with increasing gel thickness due to longer diffusion path [19,22-24]. Moreover, lower temperatures led to elongated drying times in several studies [16,24]. There are also a few studies on kinetics of supercritical drying of organic gels. GarcíaGonzález et al. compared the drying profiles of starch alcogels in the form of cylindrical monoliths and spherical particles [25]. Spherical particles could be dried much faster than monoliths. Lazrag et al. studied supercritical drying of cylindrical organic gels which were synthesized using an amino-acid-type organogelator of fibrillary structure where the solvent was tetralin [26]. Drying time was found to decrease with increasing $\mathrm{scCO}_{2}$ flow rate and decreasing gel thickness. Selmer et al. prepared cylindrical whey protein alcogels with a diameter of $14.2 \mathrm{~mm}$ and length of $9.1 \mathrm{~mm}$ and performed in situ measurements to follow their drying kinetics using Raman spectroscopy [27]. They found that the initial transfer of $\mathrm{CO}_{2}$ into gel was fast and a significant amount of $\mathrm{CO}_{2}$ was detected at the center of the gel after five minutes.

Theoretical investigations on drying kinetics using mathematical models were also carried out. In the early modeling efforts, supercritical drying was treated as a purely diffusive process described by Fick's second law [10]. A more realistic approach was later developed for the description of supercritical drying. The mass transfer of the solvent in the gel phase was treated as a diffusive process described by Fick's second law with an effective diffusion coefficient. However, additional transport mechanisms were also taken into account. At the mass transfer boundary layer at the surface of the gel, convective mass transfer of the solvent to the flowing fluid stream was considered with the use of a mass transfer coefficient. For the fluid phase flowing around the gel, the mass transport of the solvent was described by convection due to flow and axial dispersion. The partial differential equations for the solvent in the fluid inside the gel was coupled to that of the solvent in the flowing fluid phase and solved by using proper initial and boundary conditions yielding the concentration of solvent in the effluent stream from the supercritical dryer as a function of time. Griffin et al. used this approach by (i) neglecting the axial dispersion in the fluid phase, (ii) assuming no-slip condition at the surface of the gel, and (iii) introducing a composition-dependent diffusivity term for the drying of a monolithic silica alcogel with annular geometry and laminar flow of $\mathrm{scCO}_{2}$ inside the vessel [19]. Their model was in agreement with experimental data although the amount of ethanol extracted was underestimated during the early phases of drying process and overestimated during the later drying phases. Özbakır et al. incorporated a convective mass transfer term describing the transfer of solvent at the mass transfer boundary layer from the surface of the gel and neglected axial dispersion for the drying of monolithic cylindrical silica alcogel [23]. The good agreement between experimental data and model simulations using mass transfer coefficients calculated from literature correlations indicated that the proposed model was more appropriate for reproducing the experimental supercritical drying data.

Kinetics of supercritical drying of gels in the form of particles was not investigated in detail either experimentally or theoretically until the recent studies of Selmer et al [27,28]. They used differential mass balances for spherical gel particles and the fluid phase around the gel particles. All modes of mass transport including diffusion, convective mass transfer, convection and axial dispersion, were taken into account in developing the mathematical model. There was an underestimation of the drying profiles for the early phases of drying. These deviations were attributed to the simplified description of the hydrodynamics in the packed bed. Simulations using the proposed model showed that staying in the diffusion-limited region near to the transition Biot number was essential to minimize the drying duration and $\mathrm{CO}_{2}$ consumption. Therefore, convective mass transfer contribution to the drying kinetics should be accounted for accurate modeling and optimization of the drying process.

Mass transfer coefficients are usually calculated using correlations. An empirial correlation in terms of dimensionless numbers for the estimation of the mass transfer coefficients in supercritical drying of gels in a packed bed does not exist. On the other hand, for modeling supercritical extraction from various matrices, mass transfer coefficients are estimated from several empirical correlations in terms of dimensionless numbers [29-34] Tan et al. proposed a Sherwood number correlation derived from experiments carried out under supercritical conditions for the first time [34]. Later, modified versions of this correlation have been derived and utilized in several studies [29,30]. However, one of the key differences between the supercritical drying and the supercritical extraction processes is the amount of solvent in the solid medium (wet-gel). Typical extract concentrations in various matrices are around a few percent for supercritical extraction processes in contrast to a value of $90 \mathrm{wt} \%$ for most of the supercritical drying process due to highly porous nature of gels [35]. Therefore, there is a need to develop a mass transfer coefficient correlation for supercritical drying of particles.

In this study, we investigated the kinetics of supercritical drying of polysaccharide gel particles in a packed bed. Spherical calcium alginate alcogel particles with various sizes and porosity were used. Concentration of the solvent, ethanol, in the effluent stream at the exit of the drying vessel was measured as a function of time. The effect of temperature, pressure and $\mathrm{scCO}_{2}$ flow rate, and gel size on drying profiles were studied. A correlation for mass transfer coefficients for supercritical drying of alcogel particles in a packed bed was developed by fitting kinetic data to a physically realistic mathematical model. This work is the first effort on describing the kinetics of drying of polysaccharide aerogel particles which are currently attracting increasing attention for use in applications such as flavor encapsulation, controlled drug release and humidity removal $[9,13,36]$.

\section{Materials and methods}

\subsection{Materials}

Alginic acid sodium salt from brown algae (medium viscosity) and 
calcium chloride (anhydrous granular, > 93\%) were obtained from Sigma-Aldrich ${ }^{\circledR}$. Ethanol (99.9\% purity) was purchased from Isolab. $\mathrm{CO}_{2}$ was obtained from Air Liquide and had a stated purity of $99.9 \%$.

\subsection{Preparation of spherical calcium alginate beads}

Spherical calcium alginate gel particles were synthesized by dripping a $1.5 \mathrm{wt} \%$ aqueous alginate solution into a $0.2 \mathrm{M}$ aqueous $\mathrm{CaCl}_{2}$ solution with constant stirring at $200 \mathrm{rpm}$. Hydrogel beads were then placed in a distilled water bath. After that, hydrogel beads were subjected to a stepwise solvent-exchange procedure with ethanol for a duration of $2 \mathrm{~h}$ at each step $(10 \%, 30 \%, 50 \%, 70 \%, 90 \%$ and $100 \%$ ethanol by vol., respectively) to prevent excessive shrinkage of beads. Before supercritical drying, gels were kept in fresh ethanol (99.9\% purity) for $24 \mathrm{~h}$.

\subsection{Supercritical drying of calcium alginate alcogels with $\mathrm{scCO}_{2}$}

Supercritical drying of synthesized calcium alginate alcogels was performed in an Applied Separations Speed SFE unit (tubular vessel, length $=15.94 \mathrm{~cm}$, diameter $=1.43 \mathrm{~cm}$, volume $=26 \mathrm{ml}$ ). A schematic diagram of the drying unit used in this study is shown in Fig. 1. The vessel (item 6 in Fig. 1) was initially preheated to the desired temperature and filled with alcogel beads. Sufficient amount of ethanol to cover the whole packed bed of particles was added in order to prevent possible evaporation of the solvent from the alcogel surface which could lead to shrinkage of the gel beads. The vessel was then heated to the drying temperature. After rapid pressurization by opening the inlet valve to the vessel, the valve at the exit of the vessel was opened. Then, the desired flow rate of $\mathrm{CO}_{2}(2-4 \mathrm{~L} / \mathrm{min}$ at ambient conditions, $1 \mathrm{~atm}$ and $298 \mathrm{~K}$ ) was adjusted using a micro-metering valve. Ethanol started coming out from the vessel immediately and was collected in a vial immersed in a cooling bath composed of dry ice-acetone mixture at $-75^{\circ} \mathrm{C}$. In doing so, ethanol-rich liquid phase was collected in the vial whereas $\mathrm{CO}_{2}$-rich gas phase was vented out. Mass balance calculations indicated that $99.88 \%$ of ethanol can be recovered at this temperature [23]. When the amount of collected ethanol in the vial was approximately equal to the amount of excess ethanol initially added to the vessel, the vial was replaced with an empty one. Time "zero" in both concentration and percent removal plots refers to this time. The ethanol in the first vial was assumed to be the excess ethanol placed in the vessel. The collection time in the first vial lasted usually anywhere from 1 to 2 min which was much shorter than the duration of a typical drying experiment (i.e., $30 \mathrm{~min}$ ). Ethanol extracted from the alcogel was discretely collected in separate vials within certain time intervals and weighed.

The concentration of ethanol in the effluent stream at the extraction conditions, EC, $C_{E t O H-E C}$ was calculated by dividing the mass of ethanol collected in the vial, $m_{E t O H}$, by the molecular weight of ethanol, $M_{w, E t O H}$, the time interval of collection, $\Delta t$, and the volumetric flow rate of the effluent stream at extraction conditions, $Q_{\text {mixture }-E C}$.

$C_{E t O H-E C}=\frac{m_{E t O H}}{Q_{\text {mixture }-E C} \times M_{w, E t O H} \times \Delta t}$

$Q_{\text {mixture-EC }}$ was calculated by adding the volumetric flow rates of ethanol, $Q_{E t O H-E C}$, and $\mathrm{CO}_{2}, Q_{C O 2-E C}$, assuming that $\mathrm{CO}_{2}$ and ethanol formed ideal mixtures at these conditions.

$Q_{\text {mixture-EC }}=Q_{E t O H-E C}+Q_{C O 2-E C}$

$Q_{E t O H-E C}$ and $Q_{C O 2-E C}$ were calculated from the experimentally determined volumetric flow rate of ethanol at ambient conditions, $Q_{E t O H-a m b}\left(m_{E t O H} /\left(\rho_{E t O H} \times \Delta t\right)\right.$, where $\rho_{E t O H}$ is the density of ethanol at ambient conditions) and volumetric flow rate of $\mathrm{CO}_{2}$ at ambient conditions, $Q_{\mathrm{CO} 2-\mathrm{amb}}(2-4 \mathrm{~L} / \mathrm{min})$ by material balances around the micrometering valve for ethanol and $\mathrm{CO}_{2}$, given by:

$Q_{E t O H-E C}=\bar{V}_{E t O H-E C} \times \frac{Q_{E t O H-a m b}}{\bar{V}_{E t O H-a m b}}$

$Q_{C O 2-E C}=\bar{V}_{C O 2-E C} \times \frac{Q_{C O 2-a m b}}{\bar{V}_{C O 2-a m b}}$

where $\bar{V}_{E t O H-E C}$ and $\bar{V}_{C O 2-E C}$ are molar volumes of ethanol and $\mathrm{CO}_{2}$ at the extraction conditions, and $\bar{V}_{E t O H-a m b}$ and $\bar{V}_{C O 2-a m b}$ are molar volumes of ethanol and $\mathrm{CO}_{2}$ at ambient conditions.

Drying was continued until no ethanol could be collected in the vial, and the vessel was then slowly depressurized to ambient pressure at the set drying temperature. The dry aerogel particles were finally collected from the vessel.

Drying time for complete drying of small gel particles is much shorter than that in drying of large monoliths. Therefore, the concentration of ethanol at the exit stream decreases very rapidly and should be measured correctly in order to have reliable drying kinetic profiles. The early phases of drying are particularly important since drying occurs faster in these early phases. One important advantage of our experimental setup is the flexibility of the sampling interval during concentration measurement of ethanol in the exit stream. We used short intervals, 1 or $2 \mathrm{~min}$, for collection of ethnaol in the vials for the early phases of drying to measure the ethanol concentration accurately.

Two experiments at identical operating conditions were carried out

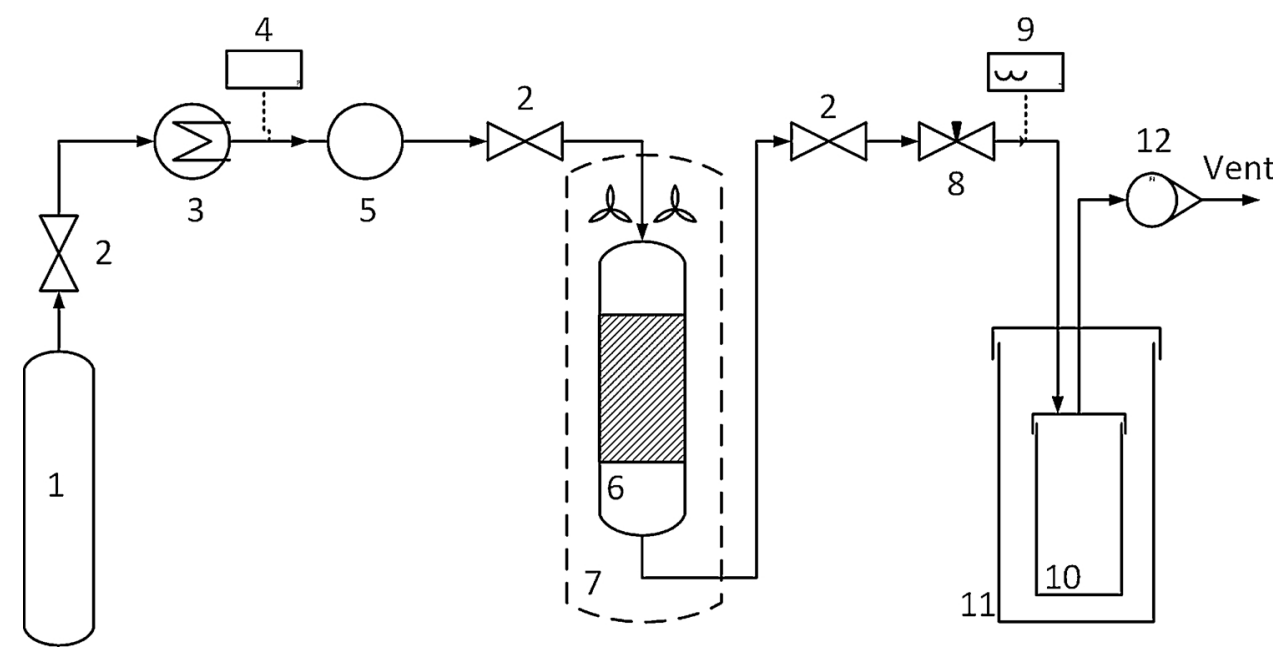

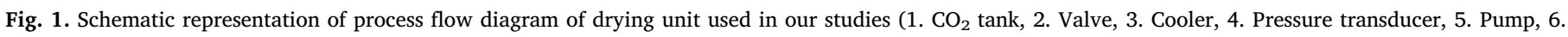
Tubular extraction vessel, 7. Oven, 8. Micro-metering Valve, 9. Thermocouple, 10. Sample collection vial, 11. Dry ice cooling bath, 12. Rotameter [23]. 

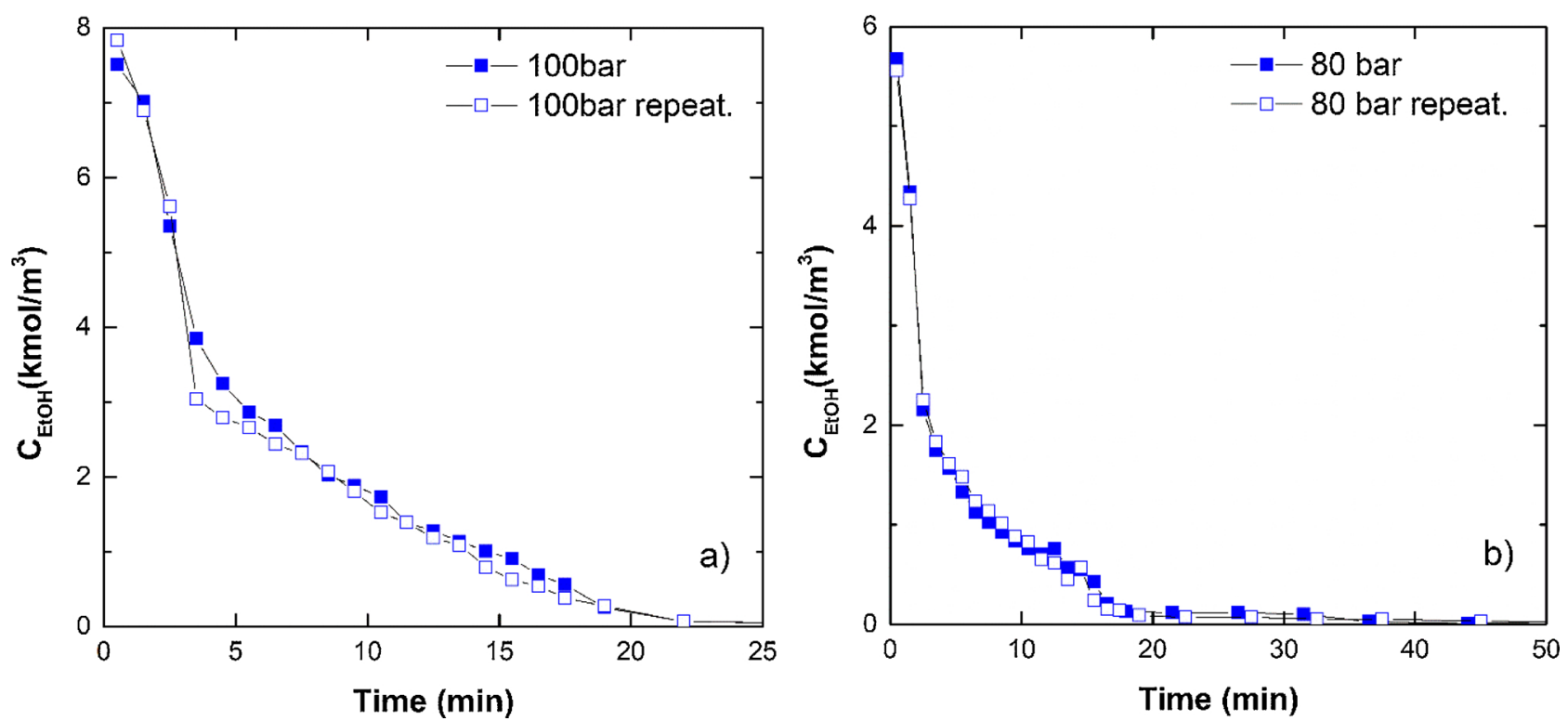

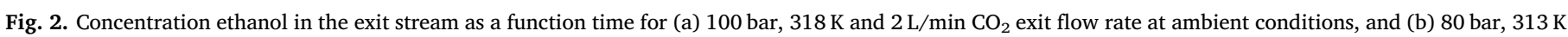
and $2 \mathrm{~L} / \mathrm{min} \mathrm{CO}_{2}$ exit flow rate at ambient conditions.

Table 1

Comparison of the initial and the final mass of the system for experiments at $100 \mathrm{bar} 318 \mathrm{~K}$ and 80 bar $318 \mathrm{~K}$ with $2 \mathrm{~L} / \mathrm{min}$ flow rate of $\mathrm{CO}_{2}$.

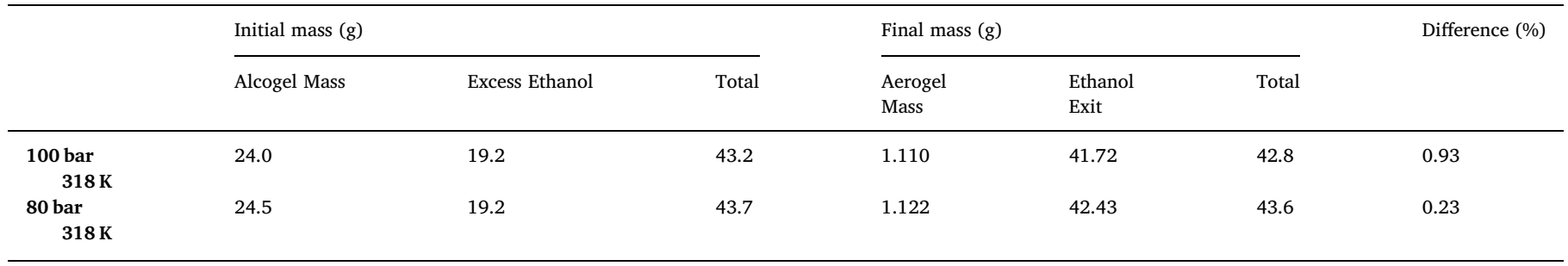

to evaluate the reproducibility of the data drying profiles. Fig. 2 shows that the concentration profiles measured in these experiments (halffilled tubular vessel, length $=12.623 \mathrm{~cm}$, diameter $=3.175 \mathrm{~cm}$, volume $=100 \mathrm{ml}$ ) were almost identical indicating excellent reproducibility. The small differences observed in concentrations may be attributed to the small delays in changing the sampling vials. Table 1 compares the total mass of alcogel particles placed in the vessel and added excess ethanol with the total mass of aerogel particles and ethanol collected during the full course of experiments. The difference between the two amounts was found to be less than $1 \%$ for both experiments. For all the other experiments carried out in this study, material balance closures for ethanol were better than $3 \%$.

\section{Results and discussions}

\subsection{Effect of operating conditions on drying}

Effects of changing $\mathrm{CO}_{2}$ flow rate, temperature and pressure on drying process were investigated. For the investigation of the effect of $\mathrm{scCO}_{2}$ flow rate, experiments were carried out with three different exit flow rates which were 2,3 and $4 \mathrm{~L} / \mathrm{min}$ at ambient conditions. The temperature and pressure at extraction conditions were $318 \mathrm{~K}$ and $100 \mathrm{bar}$, respectively. Flow rate of the entering $\mathrm{scCO}_{2}$ was found to be affecting both concentration profiles at the exit stream and drying time. Fig. 3 shows that the effluent concentration decreased faster with increasing exit flow rate from $2 \mathrm{~L} / \mathrm{min}$ to $4 \mathrm{~L} / \mathrm{min}$. Around $40 \%$ of the ethanol in the gel was removed in the very first minute of the drying at all flow rates. This was due to both the short diffusion path lengths and to the spherical geometry of the alcogels since a larger portion of the total ethanol volume in the wet-gel is close the gel surface in contact with flowing fluid stream. If the spherical particle is hypothetically divided into five shells with equal thicknesses, the outmost shell contains almost $50 \%$ of the total ethanol in the pores to the gel. Therefore, the behavior of rapid decrease in the concentration curves can be partly attributed to the spherical geometry and small particle size. The pronounced effect of flow rate on the drying kinetics implies the importance of convective mass transfer on the drying kinetics.

The drying behavior at two different pressures were investigated at $310 \mathrm{~K}$ with a $\mathrm{CO}_{2}$ exit flow rate of $3 \mathrm{~L} / \mathrm{min}$ and at $318 \mathrm{~K}$ with a $\mathrm{CO}_{2}$ exit flow rate of $2 \mathrm{~L} / \mathrm{min}$. Fig. 4a shows as pressure increases, concentration increases at a particular time. However, when this data is converted to percent removal data, this trend does not hold anymore with drying time decreasing in the order $200 \mathrm{bar} \approx 100 \mathrm{bar}>150 \mathrm{bar}$, as indicated in Fig. 4b.

Similarly, the drying behavior at two different temperatures were investigated at 100 bar and 150 bar with a $\mathrm{CO}_{2}$ exit flow rate of $2 \mathrm{~L} /$ min. Fig. 5 shows that increase in temperature speeds up the drying, shifting both curves in Fig. $5 \mathrm{~b}$ to the left.

The experiments were carried out to investigate the changes of drying profiles at a constant density of inlet $\mathrm{CO}_{2}$ stream. A set of temperature and pressure values were selected providing nearly identical $\mathrm{CO}_{2}$ densities. Experiments were performed at 85 bar and $310 \mathrm{~K}$, $100 \mathrm{bar}$ and $318 \mathrm{~K}, 125 \mathrm{bar}$ and $331 \mathrm{~K}, 150 \mathrm{bar}$ and $344 \mathrm{~K}$, and $170 \mathrm{bar}$ and $354 \mathrm{~K}$ keeping the $\mathrm{CO}_{2}$ exit flow rate at $2 \mathrm{~L} / \mathrm{min}$. Density of $\mathrm{scCO}_{2}$ is equal to $500 \mathrm{~kg} / \mathrm{m}^{3}$ at these conditions. Concentration profiles and percent removal curves in Fig. 6 indicate that increasing temperature and pressure at a constant density resulted in faster drying kinetics. 

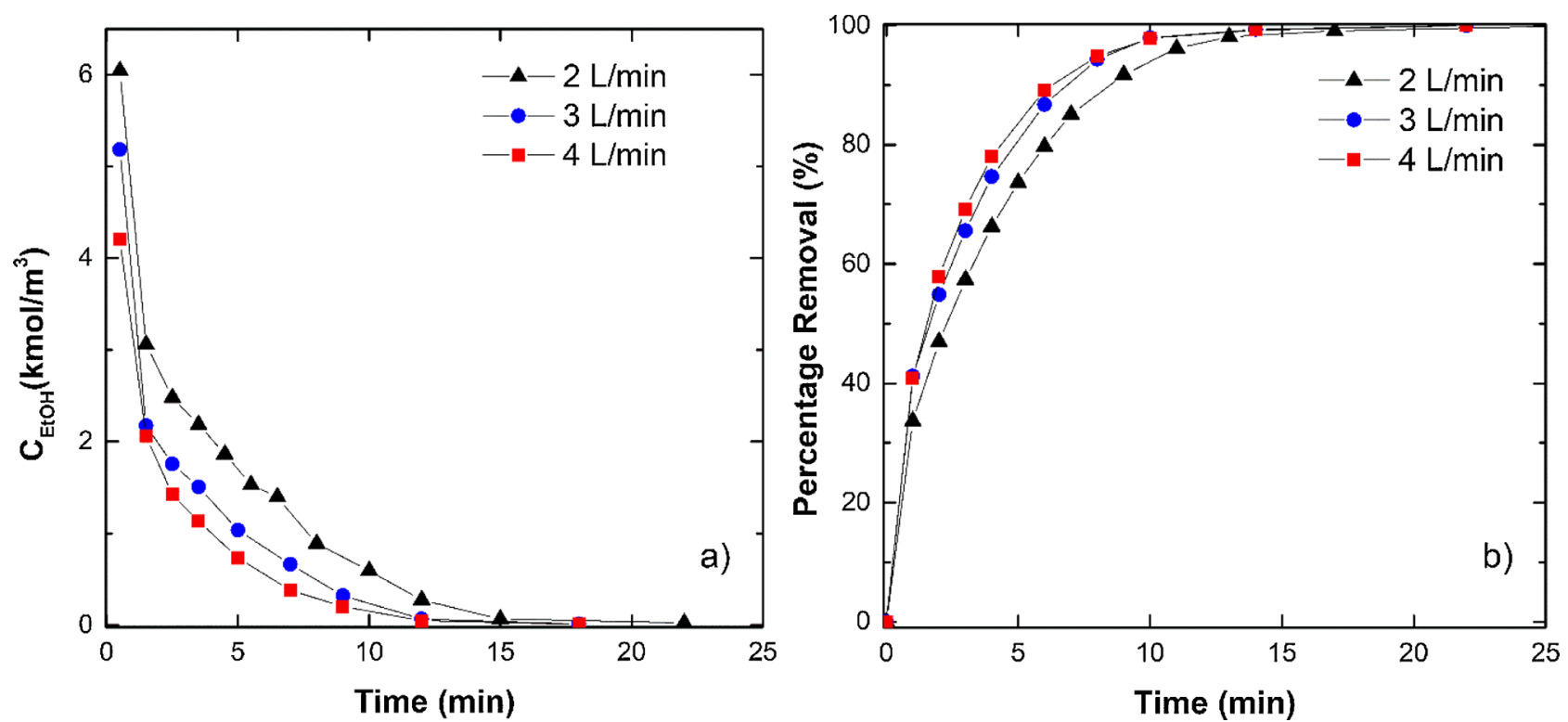

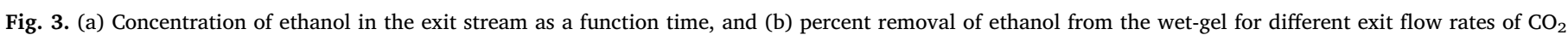
measured at ambient conditions.

\subsection{Effect of particle size on drying}

The effect of particle size was investigated by using alcogels with two different diameters, $d_{p}$. Alcogels with a diameter of $2.1 \mathrm{~mm}$ were synthesized by dripping the alginate solution using a needle with a narrow tip. Results in Fig. 7 were found to be consistent with previous findings in the literature on the effect of gel thickness on drying kinetics $[19,22,24]$. We observed a very fast drying when the particle size was decreased from $4.5 \mathrm{~mm}$ to $2.1 \mathrm{~mm}$. Decreased diffusion path lengths was the main cause of the fast drying behavior.

\subsection{Modeling of drying of spherical calcium alginate alcogel particles}

Mass transfer in the system, see Fig. 8, was represented using a physical model which consisted two coupled partial differential equations, one for the solvent in the fluid phase in the alcogel and the other

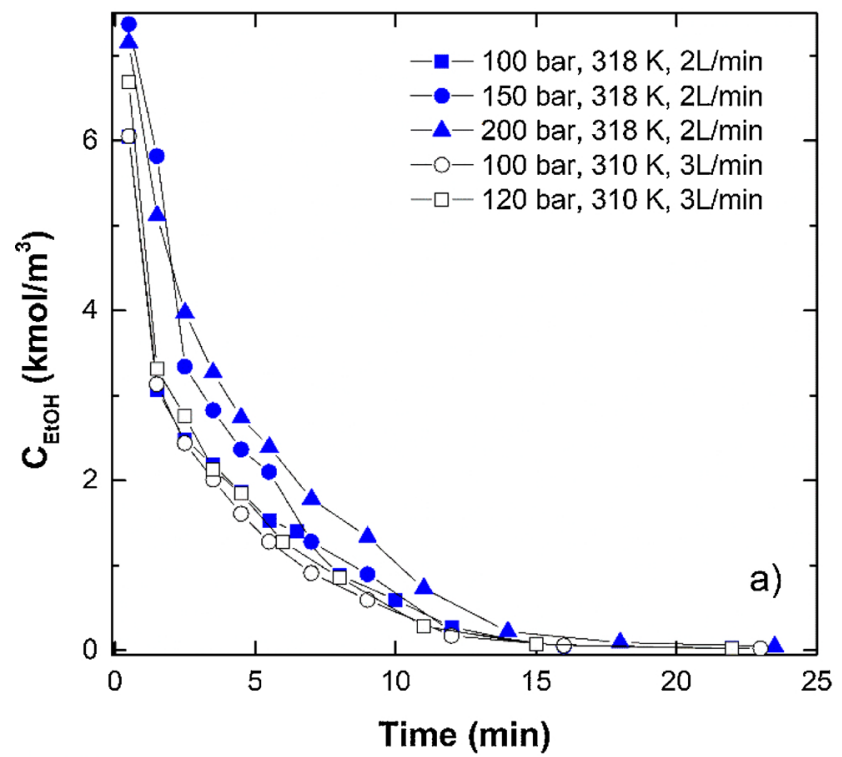

for the solvent in the fluid phase flowing around the gel particles. The direction of mass transfer of ethanol for the flowing fluid stream and for the fluid in the gel particles is schematically shown in Fig. 8. Diffusion of ethanol from the gel to the surface of the gel particles was described by Fick's second law. Mass transfer of ethanol from the surface of the particles into the flowing fluid stream, and convection and axial dispersion of ethanol in the flowing fluid stream were taken into account for the flowing fluid phase.

The partial differential equation governing mass transfer of the ethanol inside a spherical gel is given by;

$\frac{\partial C_{s}}{\partial t}=\frac{1}{r^{2}} \frac{\partial}{\partial r}\left(r^{2} D_{e} \frac{\partial C_{s}}{\partial r}\right)$

where $C_{s}$ is concentration of ethanol inside the fluid in the gel, $D_{e}$ is a concentration dependent effective diffusion coefficient of ethanol in $\mathrm{scCO}_{2}, \mathrm{t}$ is time, and $\mathrm{r}$ is the radial position.

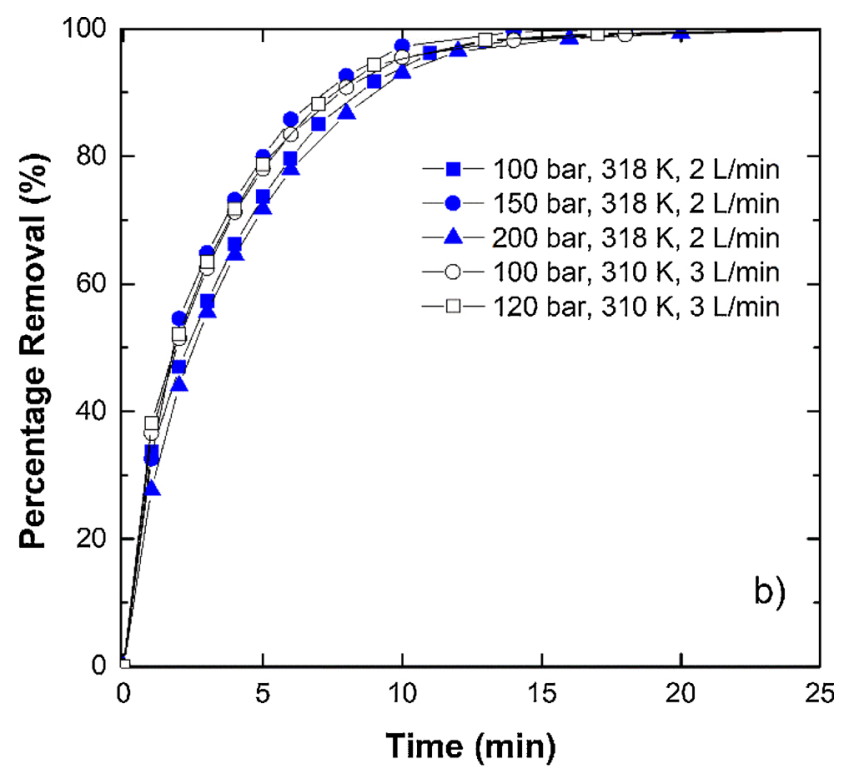

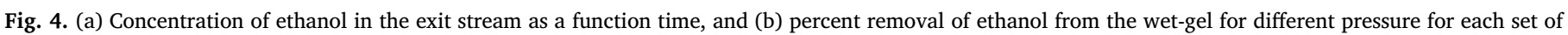
other operating conditions. 

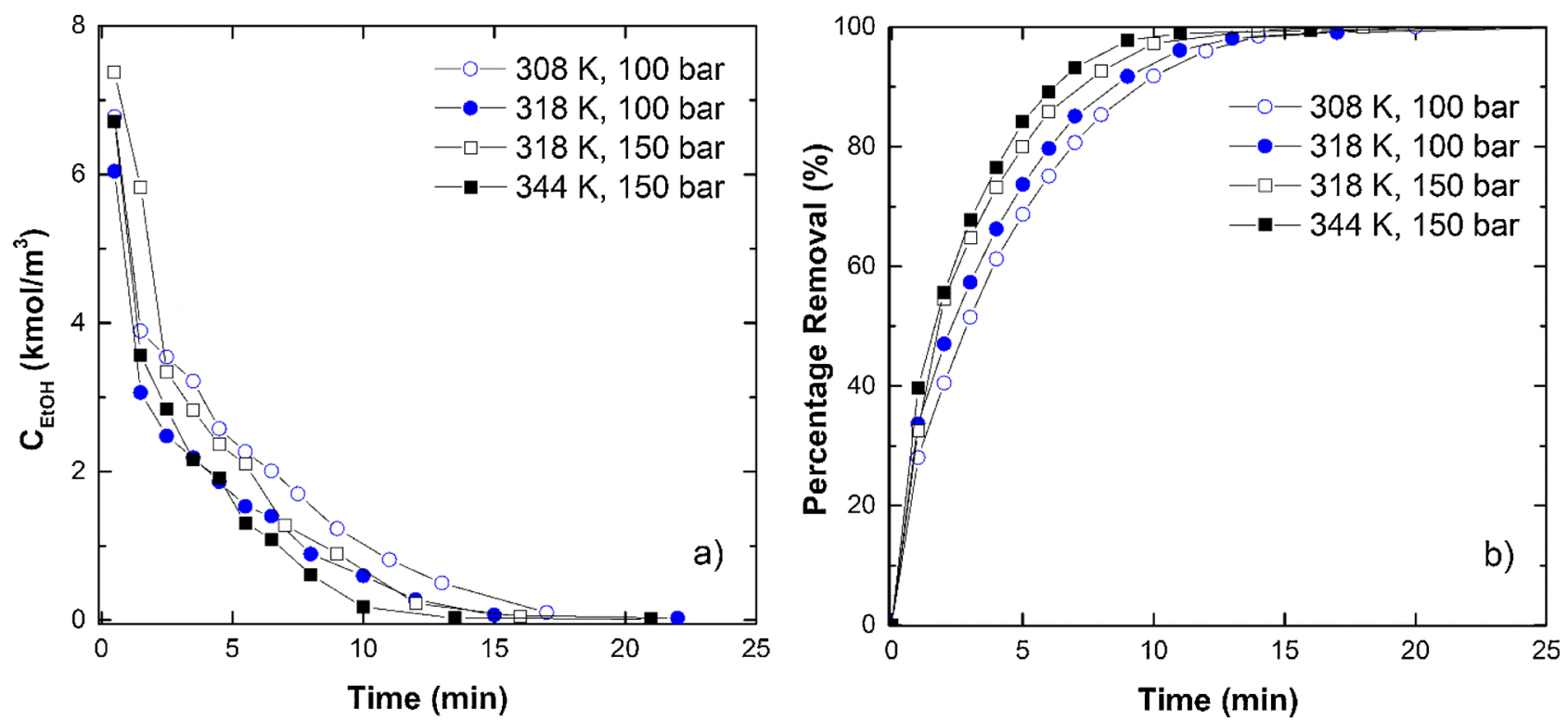

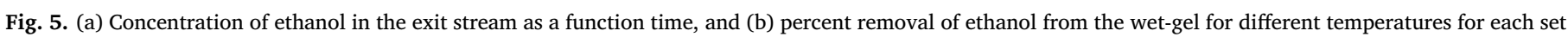
of other operating conditions.

The initial condition and the boundary conditions for Eq. 5 were taken as;

$C_{s}=C_{s 0}$ at $t=0$

$\frac{\partial C_{s}}{\partial r}=0$ at $r=0$

$D_{e} \frac{\partial C_{s}}{\partial r}=k_{f}\left(C_{f}-C_{s R}\right)$ at $r=R$

where $C_{f}$ is concentration of ethanol in the flowing fluid phase, $R$ is the radius of the gel, $C_{s R}$ is the concentration of ethanol at the surface of the gel, that is $C_{S R}=C_{S}$ at $r=R$.

Eq. 8 indicates that there is convective mass transfer from the surface of the gel $(r=R)$ into the flowing fluid phase governed by the external mass transfer coefficient $k_{f}$. Initially, there was pure ethanol inside the gel particles (Eq. 6). Symmetry boundary condition at the center of the spherical particle was implemented as given in Eq. 7.

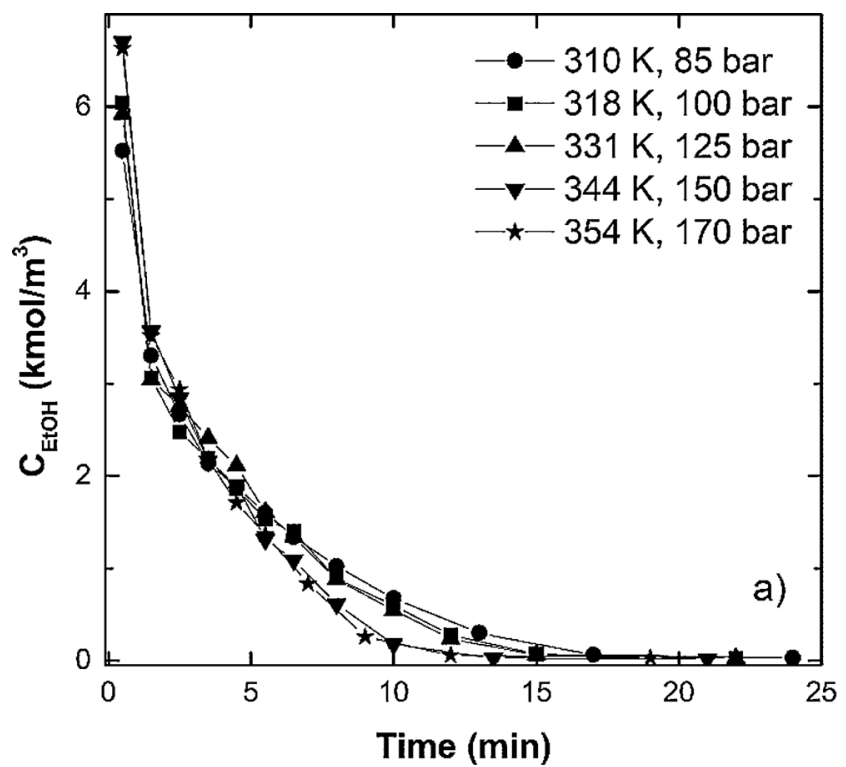

The partial differential equation obtained from a mass balance in a differential volume element in the flowing fluid phase outside the gel particles is given by;

$\frac{\partial C_{f}}{\partial t}=D_{L} \frac{\partial^{2} C_{f}}{\partial z^{2}}-u_{0} \frac{\partial C_{f}}{\partial z}-\frac{3\left(1-\varepsilon_{b}\right)}{\varepsilon_{b}} \frac{1}{R} k_{f}\left(C_{f}-C_{S R}\right)$

where $C_{f}$ is concentration of ethanol in the flowing fluid phase, $D_{L}$ is axial dispersion coefficient of ethanol, $\varepsilon_{b}$ is the porosity of the packed bed, $k_{f}$ is the external mass transfer coefficient, and $u_{0}$ is the interstitial velocity of the flowing fluid phase. The first term at the right hand side of Eq. 9 denotes the axial dispersion of ethanol governed by the axial dispersion coefficient $D_{L}$, the second term shows the mass transfer of ethanol by convection in the $\mathrm{z}$ direction in the vessel, and the last term represents the mass transfer taking place from the surface of the gel particles.

The initial condition and the boundary conditions for Eq. 9 were as

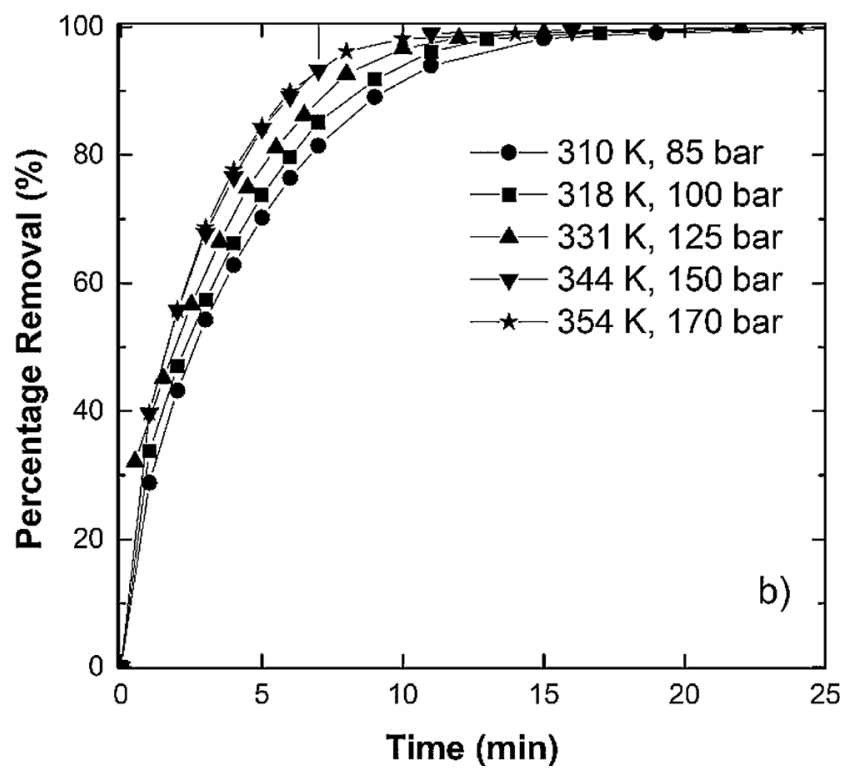

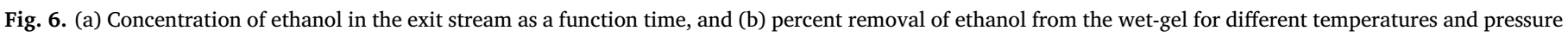
for a constant density of inlet $\mathrm{scCO}_{2}$. 

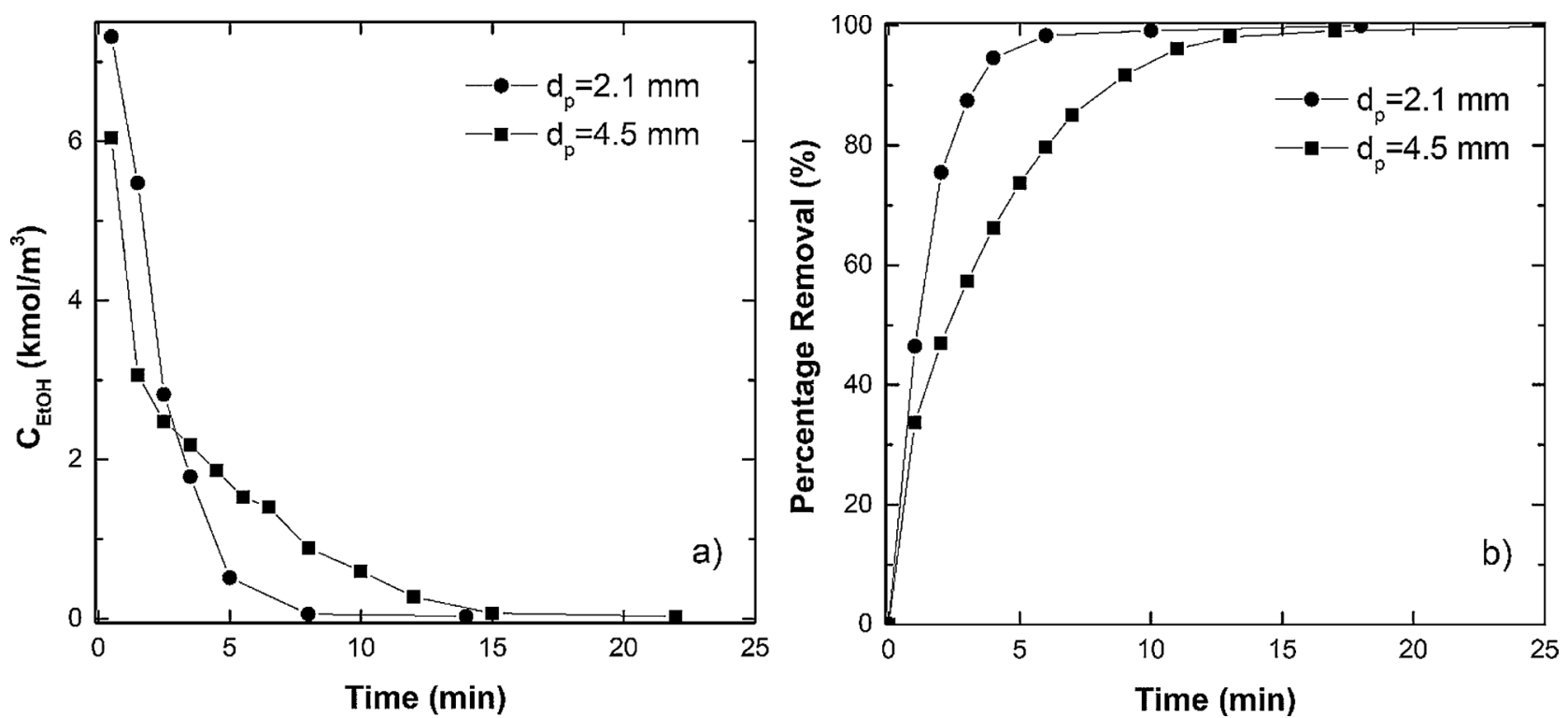

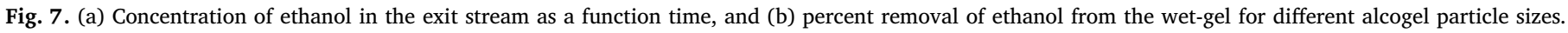
Temperature, pressure and $\mathrm{CO}_{2}$ exit flow rate were set to $318 \mathrm{~K}, 100$ bar and $2 \mathrm{~L} / \mathrm{min}$, respectively.

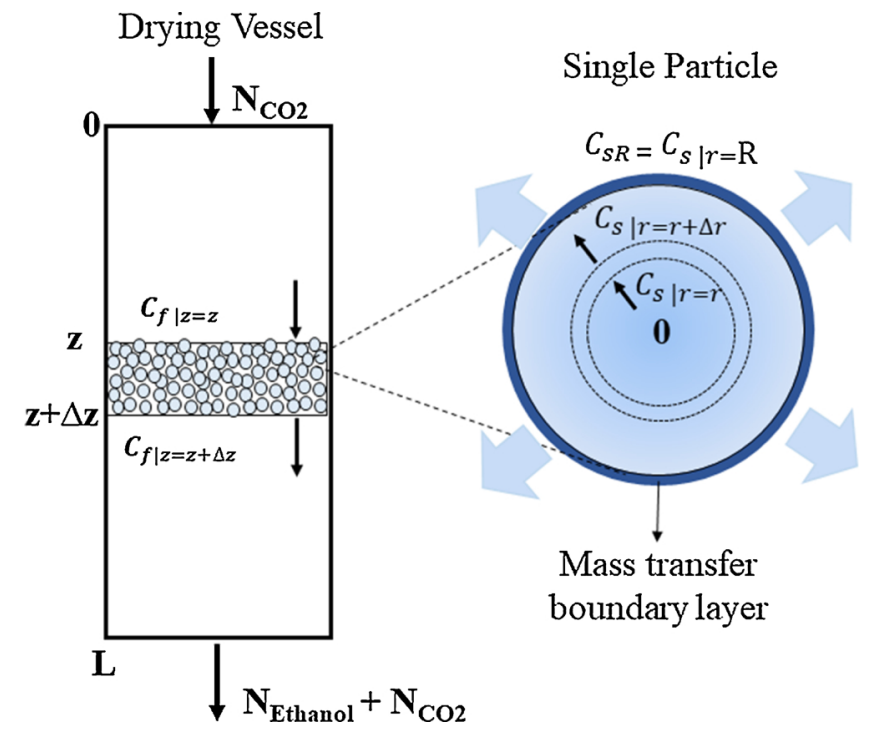

Fig. 8. Schematic representation of the direction of mass transfer of ethanol for the flowing fluid stream and for the fluid in the gel particles.

follows;

$C_{f}=C_{f 0}$ at $t=0$

$u_{0} C_{f}-D_{L} \frac{\partial C_{f}}{\partial z}=0 \mathrm{at} z=0$

$\frac{\partial C_{f}}{\partial z}=0 \mathrm{at} z=L$

Initially, the pores in the gel and the void volume of the extraction vessel were assumed to be filled with pure ethanol (Eq. 10). Danckwerts boundary condition was implemented for the flowing fluid phase at the top of the drying vessel, $\mathrm{z}=0$, indicating the dispersion of ethanol is counterbalanced by the convective term to prevent ethanol loss (Eq. 11.). Concentration of ethanol at the exit of the vessel $(z=L)$ does not change with position. (Eq. 12.).

Numerical method of lines (NMOL) was implemented by converting the coupled partial differential equations, Eqs. 5 and 9, into a coupled set of differential-algebraic equations by discretizing only the spatial dimension via finite difference method. The temporal dimension, $t$, was allowed to be continuous. Then, available built-in ordinary differential equation (ODE) solvers in MATLAB were utilized to solve the ODEs obtained from discretization. The model thus yielded concentration of ethanol in the fluid phase inside the particles, $C_{s}$, as a function of $\mathrm{r}, \mathrm{z}$, and time and concentration of ethanol in the fluid phase flowing around the particles, $C_{f}$, as a function of $\mathrm{z}$ and time. The inlet volumetric flow rate of $\mathrm{CO}_{2}$ at extraction conditions varied as a function of time in solving model equations. In experiments, the volumetric flow rate of $\mathrm{CO}_{2}$ at the exit at ambient conditions was kept constant $(2-4 \mathrm{~L} / \mathrm{min})$. The volumetric flow rate of $\mathrm{CO}_{2}$ at the inlet of the bed was taken as the sum of the volumetric flow rate of ethanol and $\mathrm{CO}_{2}$ at the exit of the bed at extraction conditions. The inlet volumetric flow rates of $\mathrm{CO}_{2}$ as a function of time for all of the experiments can be found in Table S1 in Supplementary Information.

In order to compare the model results with experimental data, a set of calculations was performed after the solving differential equations. First, the amount of ethanol collected at the exit of the vessel as a function of time was determined by taking the integral of mass flow rate of ethanol at the exit of the vessel $\left(Q_{\text {mixture }-E C} \times C_{f}\right.$ at $\left.z=L\right)$ versus time curve. Then, the time when the amount of ethanol collected was equal to the amount of initially added excess ethanol to the vessel $\left(t_{\text {excess }}\right)$ was determined. This time was taken as time zero and the other time values were adjusted by subtracting $t_{\text {excess }}$. $C_{f}$ values at $\mathrm{z}=\mathrm{L}$ at each time calculated from the model with time correction as described above were compared with the concentrations calculated from experimental data as described in the Experimental section.

\subsubsection{Parameter estimation}

Parameters in the constructed model were determined by measurement and correlations available in the literature. Table 2 summarizes the estimated model parameters, estimation method and relevant references.

Bulk density and skeletal density of the aerogel particles were used to calculate the particle porosity as follows:

$\varepsilon=1-\frac{\rho_{\text {bulk }}}{\rho_{\text {sketal }}}$

Bulk density was calculated from the average values of measured weight and diameter of the spherical aerogels. Skeletal density of the gel was assumed to be equal to the density in the crystallized state 
Table 2

Summary of the parameters used in the model.

\begin{tabular}{|c|c|c|c|}
\hline Paramater & Value & Estimation Method & References \\
\hline Particle porosity, $\varepsilon$ & 0.965 & Density measurements & - \\
\hline Bed porosity, $\varepsilon_{b}$ & 0.42 & Volume measurements & - \\
\hline Tortuosity, $\tau$ & $1 / \varepsilon$ & Literature correlation & [37] \\
\hline Density \& Viscosity, & Varies with $\mathrm{T}, \mathrm{P}$ & Literature data & [38] \\
\hline \multicolumn{4}{|l|}{$\rho_{\mathrm{CO}_{2}} \& \mu_{\mathrm{CO}_{2}}$} \\
\hline Effective diffusion coefficient, $D_{e}$ & $D_{e}=D_{o g}^{\left(1-x_{\mathrm{CO}_{2}}\right)} \times D_{o l}^{x_{\mathrm{co} 2}} \times \varepsilon / \tau$ & Literature correlation & [39] \\
\hline Binary diffusion coefficient of ethanol in $\mathrm{scCO}_{2}$ at infinite dilution, $D_{o g}$ & $\begin{array}{l}D_{\text {og }}=T \times\left(-9.434 \times 10^{-7} \times \rho_{C_{2}}\right. \\
\left.+1.296 \times 10^{-6}\right)\end{array}$ & Literature correlation & {$[40]$} \\
\hline Binary diffusion coefficient of $\mathrm{CO}_{2}$ in ethanol at infinite dilution, $D_{o l}$ & $D_{o l}=336.5 \times 10^{-9} \exp \left(\frac{-1314.7}{T}\right)$ & Literature correlation & [41] \\
\hline \multirow[t]{2}{*}{ Axial dispersion coefficient, $D_{L}$} & $D_{L}=\frac{u_{0} \times d_{p}}{P e}$ & Literature correlation & [42] \\
\hline & $\begin{array}{l}P e=1.634 R e^{0.265} S^{-0.919} \\
R e=\frac{d_{p} u_{0} \varepsilon_{b} \rho_{C O}}{\mu_{C O_{2}}}, S c=\frac{\mu_{C O_{2}}}{\rho_{C O_{2}} D_{o g}}\end{array}$ & & \\
\hline \multirow[t]{2}{*}{ Mass transfer coefficient, $k_{f}$} & $k_{f}=\frac{S h \times D_{o g}}{d_{p}}$ & Determination of constant $\alpha, \beta$ and $\gamma$ by regression & - \\
\hline & $S h=\alpha R e^{\beta} S c^{\gamma}$ & & \\
\hline
\end{tabular}

which was $1.6 \mathrm{~g} / \mathrm{cm}^{3}[43,44]$. Tortuosity of the porous network of the gel was assumed to be a fixed parameter and equal to $1 / \varepsilon$ in accordance with the work of Wakao et al [31]. Bed porosity was estimated by filling the void volume of the drying vessel with ethanol and taking the ratio of the filled ethanol volume to the total volume of the drying vessel filled with alcogels. NIST Standard Reference Database was used to calculate the density and the viscosity of $\mathrm{scCO}_{2}$, which vary with temperature and pressure [38].

Composition-dependent effective diffusion coefficients were calculated using the Vignes correlation which was used in several previous studies [23,27]. Infinite dilution binary diffusion coefficient of ethanol in $\mathrm{scCO}_{2}$ was estimated using the simple empirical correlation suggested by Magalhães et al. [40]. According to that study, average absolute relative error between the experimental data and the values calculated using the proposed correlation was $2.15 \%$ for the $\mathrm{CO}_{2}$ ethanol system [45]. For the case of binary diffusion coefficient of $\mathrm{CO}_{2}$ in ethanol at infinite dilution, the empirical correlation by Snijder et al. was utilized [41].

Axial dispersion coefficient was estimated using a Péclet number (Pe) correlation developed by Tan et al. for methane-scCO $\mathrm{CO}_{2}$ system [42]. This correlation was selected since both vessel and particle diameters and operating conditions were similar to those used in this study. Besides, calculated Pe numbers in this study fall to the studied range of $0.6-2.7$ by Tan et al. There are also several other studies which utilized this correlation successfully [46-49].

The external mass transfer coefficient, $k_{f}$, was the only regressed parameter in the model. A Sherwood number correlation for forced convection in terms of Reynolds number (Re) and Schmidt number (Sc) was proposed, and constants $\alpha, \beta$ and $\gamma$ were determined.

\subsubsection{Comparison of experimental data to model predictions and mass transfer correlations}

The constants $\alpha, \beta$ and $\gamma$ in the proposed mass transfer correlation were determined by fitting the model results to experimental kinetic data. Table 3 shows the experiments with their set temperature, pressure, and $\mathrm{CO}_{2}$ flow rate along with particle diameter. Values of $\alpha, \beta$ and $\gamma$ were estimated as $0.249,0.295$ and 0.333 , respectively, for $20<\operatorname{Re}<200$.

Figs. 9 and 10 show the comparison of experimental data and model results. There is good agreement between the model results and experimental data for all the experiments with the exceptions of experiments 5 and 10 for which model predictions were slightly off than the others. Calculated $\mathrm{R}^{2}$ values for all the experiments lie between 0.969 and 0.999 . The proposed model along with the mass transfer correlation
Table 3

Summary of the operating conditions.

\begin{tabular}{lllll}
\hline Experiment No. & Temperature, $K$ & Pressure, bar & Q $_{\mathrm{CO} 2 \text {-amb }}, \mathrm{L} / \mathrm{min}$ & $\begin{array}{l}\mathrm{d}_{\text {particle, }} \\
\mathrm{mm}\end{array}$ \\
\hline 1 & & & 2 & 4.5 \\
2 & 318.15 & 100 & 3 & 4.5 \\
3 & 318.15 & 100 & 4 & 4.5 \\
4 & 318.15 & 100 & 2 & 2.1 \\
5 & 318.15 & 100 & 2 & 4.5 \\
6 & 318.15 & 200 & 3 & 4.5 \\
7 & 310.15 & 120 & 3 & 4.5 \\
8 & 310.15 & 100 & 2 & 4.5 \\
9 & 308.15 & 100 & 2 & 4.5 \\
10 & 344.15 & 150 & 2 & 4.5 \\
11 & 318.15 & 150 & 2 & 4.5 \\
12 & 331.15 & 125 & 2 & 4.5 \\
13 & 310.15 & 85 & 2 & 4.5 \\
\hline
\end{tabular}

provides a good prediction of the experimental drying time as well as the drying kinetics. Also, the model accurately predicts the effect of changing alcogel particle size on drying kinetics.

\section{Conclusion}

Kinetics of supercritical drying of polysaccharide alcogel particles in a packed bed was investigated for the first time. Experiments were carried out at different temperatures $(308 \mathrm{~K}-354 \mathrm{~K})$, pressures ( 85 bar -200 bar), $\mathrm{CO}_{2}$ exit flow rates $(2 \mathrm{~L} / \mathrm{min}-4 \mathrm{~L} / \mathrm{min}$ ) and gel particle sizes $(2.1 \mathrm{~mm}-4.5 \mathrm{~mm})$. Increasing flow rate decreased the drying time whereas increasing particle size led to a significantly slower drying kinetics. Increase in the temperature also led to faster drying of particles. A mathematical model, which takes into account the diffusion of ethanol to the surface of gel particles, convective mass transfer of ethanol into the flowing fluid stream at the mass transfer boundary layer, convection and axial dispersion of ethanol in flowing fluid stream, was used to describe the kinetics of supercritical drying. A Sherwood number correlation was developed to estimate external mass transfer coefficients by fitting the model to experimental data. A good agreement between the experimental data and the model results was obtained. The drying kinetics depends in a complex manner on bed properties (bed porosity, length, and diameter), particle properties (particle size and particle porosity) and the operating conditions (temperature, pressure, and flow rate). The effect of all these parameters and their effects on effective diffusion coefficient, convective mass transfer coefficient and axial dispersion coefficient should be 

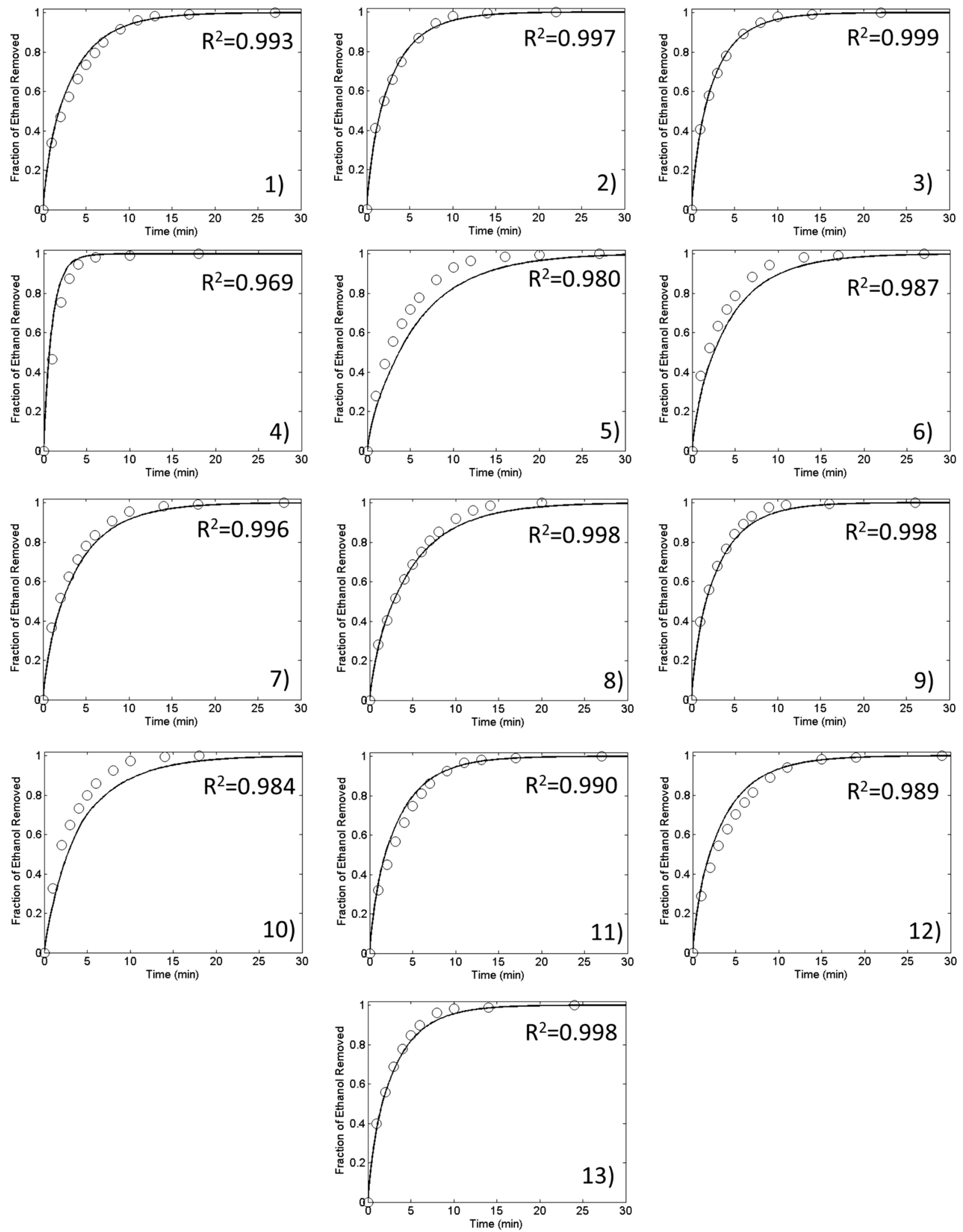

Fig. 9. Comparison of the fraction of ethanol removal curves estimated by the model with the experimental data for the experiments listed in Table 3. Straight lines indicate the model results whereas empty circles show the experimental data points. Numbers corresponds to experiment numbers denoted in Table 3. 

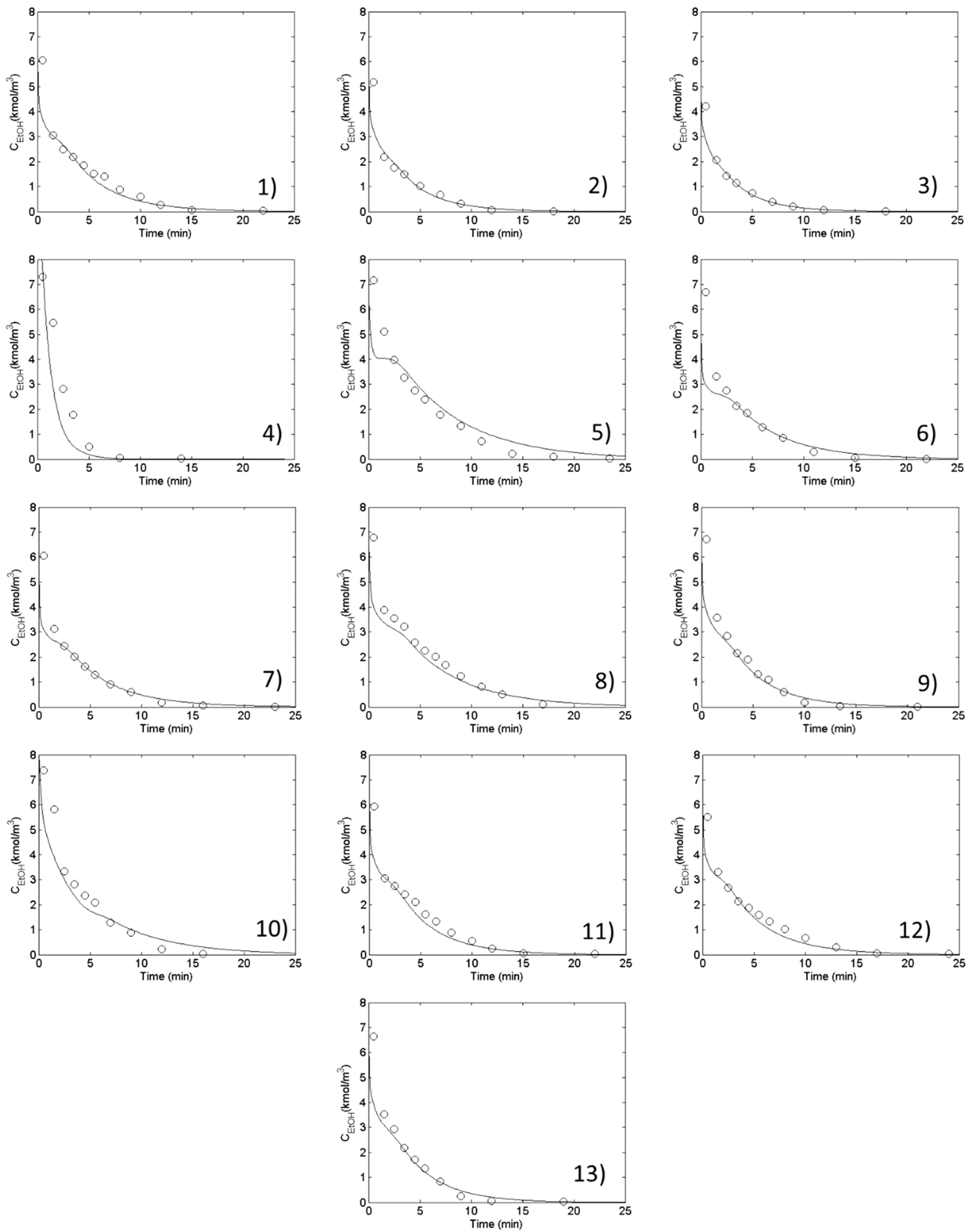

Fig. 10. Comparison of the ethanol concentrations at the exit stream estimated by the model with the experimental data for the experiments listed in Table 3 . Straight lines indicate the model results whereas empty circles show the experimental data points. Numbers corresponds to experiment numbers denoted in Table 3 . 
considered in order to understand the changes in drying profiles.

\section{Acknowledgements}

This work was supported by European Union's Horizon 2020 research and innovation programme under grant agreement No: 685648.

\section{References}

[1] M.A. Aegerter, N. Leventis, M.M. Koebel, Aerogels Handbook, Springer, New York, 2011, https://doi.org/10.1007/978-1-4419-7589-8.

[2] S.S. Kistler, Coherent expanded-aerogels, J. Phys. Chem. 36 (1931) 52-64, https:// doi.org/10.1021/j150331a003.

[3] K.I. Jensen, J.M. Schultz, F.H. Kristiansen, Development of windows based on highly insulating aerogel glazings, J. Non. Solids 350 (2004) 351-357, https://doi. org/10.1016/j.jnoncrysol.2004.06.047.

4] C. Buratti, E. Moretti, Glazing systems with silica aerogel for energy savings in buildings, Appl. Energy 98 (2012) 396-403, https://doi.org/10.1016/j.apenergy. 2012.03.062.

[5] E. Elaloui, P. Achard, B. Chevalier, J.-L. Chevalier, M. Durant, G.M. Pajonk, Improved Monolithic Aerogel for Transparent Glass Spacer in Innovative Windows, (1992), pp. 1711-1727, https://doi.org/10.1117/12.130528.

[6] A. Venkateswara Rao, D. Haranath, G.M. Pajonk, P.B. Wagh, Optimisation of supercritical drying parameters for transparent silica aerogel window applications, Mater. Sci. Technol. 14 (1998) 1194-1199, https://doi.org/10.1179/mst.1998.14. 11.1194.

[7] New Spaceloft ${ }^{\circledast}$ Insul-Cap ${ }^{\mathrm{TM}}$ From Aspen Aerogels Improves Thermal Efficiency of Wall Framing, (2007) (accessed September 12, 2017), http://news.aerogel.com/ press-releases? item $=66347$.

[8] J.L. Gurav, I.-K. Jung, H.-H. Park, E.S. Kang, D.Y. Nadargi, Silica Aerogel, Synthesis and applications, J. Nanomater. 2010 (2010) 1-11, https://doi.org/10.1155/2010/ 409310.

[9] I. Smirnova, P. Gurikov, Aerogels in chemical engineering: strategies toward tailormade aerogels, Annu. Rev. Chem. Biomol. Eng. 8 (2017) 307-334, https://doi.org/ 10.1146/annurev-chembioeng-060816-101458.

[10] İ. Şahin, Y. Özbakır, Z. İnönü, Z. Ulker, C. Erkey, Kinetics of supercritical drying of gels, Gels 4 (2018), https://doi.org/10.3390/gels4010003.

[11] C. Moreno-Castilla, F.J. Maldonado-Hódar, Carbon aerogels for catalysis applications: An overview, Carbon N. Y. 43 (2005) 455-465, https://doi.org/10.1016/j. carbon.2004.10.022.

[12] J. Stergar, U. Maver, Review of aerogel-based materials in biomedical applications, J. Solgel Sci. Technol. 77 (2016) 738-752, https://doi.org/10.1007/s10971-0163968-5.

[13] Z. Ulker, C. Erkey, An emerging platform for drug delivery: aerogel based systems, J. Control. Release 177 (2014) 51-63, https://doi.org/10.1016/j.jconrel.2013.12. 033.

[14] K. Ganesan, A. Dennstedt, A. Barowski, L. Ratke, Design of aerogels, cryogels and xerogels of cellulose with hierarchical porous structures, Mater. Des. 92 (2016) 345-355, https://doi.org/10.1016/j.matdes.2015.12.041.

[15] DOWSILTM VM-2270 Aerogel Fine Particles, (n.d.). https://consumer.dow.com/enus/pdp.dowsilTM vm-2270 aerogel fine particles.04060829z.html?tab =overview\& id $=04060829 \mathrm{z}$ (accessed September 12, 2018).

[16] A.M. Orlović, S. Petrović, D.U. Skala, Mathematical modeling and simulation of gel drying with supercritical carbon dioxide, J. Serbian 70 (2005) 125-136 http:// scindeks.ceon.rs/article.aspx? artid = 0352-51390501125O\%5Cnpapers3:// publication/uuid/C1E76FEF-7998-4759-B1BB-7353CE25B68B.

[17] P. Wawrzyniak, G. Rogacki, J. Pruba, Z. Bartczak, Diffusion of ethanol-carbon dioxide in silica gel, J. Non Solids 225 (1998) 86-90, https://doi.org/10.1016/ S0022-3093(98)00105-7.

[18] A.E. Lebedev, A.M. Katalevich, N.V. Menshutina, Modeling and scale-up of supercritical fluid processes. Part I: Supercritical drying, J. Supercrit. Fluids 106 (2015) 122-132, https://doi.org/10.1016/j.supflu.2015.06.010.

[19] J.S. Griffin, D.H. Mills, M. Cleary, R. Nelson, V.P. Manno, M. Hodes, Continuous extraction rate measurements during supercritical CO2 drying of silica alcogel, J. Supercrit. Fluids 94 (2014) 38-47, https://doi.org/10.1016/j.supflu.2014.05.020.

[20] Y. Masmoudi, A. Rigacci, P. Ilbizian, F. Cauneau, P. Achard, Diffusion during the supercritical drying of silica gels, Dry. Technol. 24 (2006) 1121-1125, https://doi. org/10.1080/07373930600778270.

[21] C.A. García-González, M.C. Camino-Rey, M. Alnaief, C. Zetzl, I. Smirnova, Supercritical drying of aerogels using CO 2: effect of extraction time on the end material textural properties, J. Supercrit. Fluids 66 (2012) 297-306, https://doi. org/10.1016/j.supflu.2012.02.026.

[22] M.J. Bommel, A.B. Haan, Drying of silica gels with supercritical carbon dioxide, J. Mater. Sci. 29 (1994) 943-948, https://doi.org/10.1007/BF00351414.

[23] Y. Özbakir, C. Erkey, Experimental and theoretical investigation of supercritical drying of silica alcogels, J. Supercrit. Fluids 98 (2015) 153-166, https://doi.org/10. 1016/j.supflu.2014.12.001.

[24] M. Mukhopadhyay, B.S. Rao, Modeling of supercritical drying of ethanol-soaked silica aerogels with carbon dioxide, J. Chem. Technol. Biotechnol. 83 (2008) 1101-1109, https://doi.org/10.1002/jctb.1996.
[25] C.A. García-González, I. Smirnova, Use of supercritical fluid technology for the production of tailor-made aerogel particles for delivery systems, J. Supercrit. Fluids 79 (2013) 152-158, https://doi.org/10.1016/j.supflu.2013.03.001.

[26] M. Lazrag, C. Lemaitre, C. Castel, A. Hannachi, D. Barth, Aerogel production by supercritical drying of organogels: experimental study and modelling investigation of drying kinetics, J. Supercrit. Fluids 140 (2018) 394-405, https://doi.org/10. 1016/j.supflu.2018.07.016.

[27] I. Selmer, A.S. Behnecke, J. Quiño, A.S. Braeuer, P. Gurikov, I. Smirnova, Model development for sc-drying kinetics of aerogels: Part 1. Monoliths and single particles, J. Supercrit. Fluids 140 (2018) 415-430, https://doi.org/10.1016/j.supflu. 2018.07.002.

[28] I. Selmer, A.-S. Behnecke, P. Farrell, A.B. Morales, P. Gurikov, I. Smirnova, Model development for sc-drying kinetics of aerogels: Part 2. Packed bed of spherical particles, J. Supercrit. Fluids (2018), https://doi.org/10.1016/j.supflu.2018.07. 006.

[29] F. Stüber, A.M. Vazquez, M.A. Larrayoz, F. Recasens, Supercritical fluid extraction of packed beds: external mass transfer in upflow and downflow operation, Ind. Eng. Chem. Res. 35 (1996) 3618-3628, https://doi.org/10.1021/ie9601514.

[30] J. Puiggené, M.A. Larrayoz, F. Recasens, Free liquid-to-supercritical fluid mass transfer in packed beds, Chem. Eng. Sci. 52 (1997) 195-212, https://doi.org/10. 1016/S0009-2509(96)00379-X.

[31] N. Wakao, S. Kagei, Heat and Mass Transfer in Packed Beds, Gordon and Breach Science Publishers, 1982, https://books.google.com.tr/books?id = Ya5hzOgC05wC.

[32] S. Zheng, X. Hu, A.-R. Ibrahim, D. Tang, Y. Tan, J. Li, Supercritical fluid drying: classification and applications, Recent Pat. Chem. Eng. 3 (2010) 230-244, https:// doi.org/10.2174/2211334711003030230.

[33] Z. Huang, X. Shi, W. Jiang, Theoretical models for supercritical fluid extraction, J. Chromatogr. A 1250 (2012) 2-26, https://doi.org/10.1016/j.chroma.2012.04.032.

[34] C.-S. Tan, S.-K. Liang, D.-C. Liou, Fluid-solid mass transfer in a supercritical fluid extractor, Chem. Eng. J. 38 (1988) 17-22, https://doi.org/10.1016/0300-9467(88) 80049-2.

[35] A. Bueno, I. Selmer, R. S.P, P. Gurikov, W. Lölsberg, D. Weinrich, M. Fricke, I. Smirnova, First evidence of solvent spillage under subcritical conditions in aerogel production, Ind. Eng. Chem. Res. 57 (2018) 8698-8707, https://doi.org/10. 1021/acs.iecr.8b00855.

[36] A. Veronovski, Z. Novak, Ž. Knez, Synthesis and use of organic biodegradable aerogels as drug carriers, J. Biomater. Sci. Polym. Ed. 23 (2012) 873-886, https:// doi.org/10.1163/092050611X566126.

[37] N. Wakao, J.M. Smith, Diffusion in catalyst pellets, Chem. Eng. Sci. 17 (1962) 825-834, https://doi.org/10.1016/0009-2509(62)87015-8.

[38] E. Shen, V.K. Siderius, D.W. Krekelberg, W.P, H.W. Hatch, NIST Standard Reference Simulation Website, NIST Stand. Ref. Database Number 173, (2018), https://doi. org/10.18434/T4M88Q (accessed June 20, 2018).

[39] A. Vignes, Diffusion in binary solutions: variation of diffusion coefficient with composition, Ind. Eng. Chem. Fundam. 5 (1966) 189-199, https://doi.org/10. 1021/i160018a007.

[40] A.L. Magalhães, P.F. Lito, F.A. Da Silva, C.M. Silva, Simple and accurate correlations for diffusion coefficients of solutes in liquids and supercritical fluids over wide ranges of temperature and density, J. Supercrit. Fluids 76 (2013) 94-114, https:// doi.org/10.1016/j.supflu.2013.02.002.

[41] E.D. Snijder, M.J.M. Te Riele, G.F. Versteeg, W.P.M. Van Swaaij, Diffusion coefficients of CO, COS, N20, and N2 in ethanol and toluene, J. Chem. Eng. Data 40 (1996) 37-39, https://doi.org/10.1021/je00017a010.

[42] C.-S. Tan, D.-C. Liou, Axial dispersion of supercritical carbon dioxide in packed beds, Ind. Eng. Chem. Res. 28 (1989) 1246-1250, https://doi.org/10.1021/ ie00092a020.

[43] M. Robitzer, A. Tourrette, R. Horga, R. Valentin, M. Boissière, J.M. Devoisselle, F. Di Renzo, F. Quignard, Nitrogen sorption as a tool for the characterisation of polysaccharide aerogels, Carbohydr. Polym. 85 (2011) 44-53, https://doi.org/10.1016/ j.carbpol.2011.01.040

[44] M. Robitzer, F. Di Renzo, F. Quignard, Natural materials with high surface area. Physisorption methods for the characterization of the texture and surface of polysaccharide aerogels, Microporous Mesoporous Mater. 140 (2011) 9-16, https://doi. org/10.1016/j.micromeso.2010.10.006.

[45] C.Y. Kong, T. Funazukuri, S. Kagei, Binary diffusion coefficients and retention factors for polar compounds in supercritical carbon dioxide by chromatographic impulse response method, J. Supercrit. Fluids 37 (2006) 359-366, https://doi.org/ 10.1016/j.supflu.2005.10.006.

[46] M.A. Falcão, R. Scopel, R.N. Almeida, A.T. do Espirito Santo, G. Franceschini, J.J. Garcez, R.M.F. Vargas, E. Cassel, Supercritical fluid extraction of vinblastine from Catharanthus roseus, J. Supercrit. Fluids 129 (2017) 9-15, https://doi.org/10 1016/j.supflu.2017.03.018.

[47] I.C.M. da Silva, W.L. dos Santos, I.C.R. Leal, Mdas G.B. Zoghbi, A.C. Feirhmann, V.F. Cabral, E.N. Macedo, L. Cardozo-Filho, Extraction of essential oil from Cyperus articulatus L. var. articulatus (priprioca) with pressurized CO2, J. Supercrit. Fluids 88 (2014) 134-141, https://doi.org/10.1016/j.supflu.2014.02.001.

[48] F. Esmaeilzadeh, R. Lashkarboluki, M. Lashkarbolooki, A. Zeinolabedini Hezave, Modeling of spearmint oil extraction in a packed bed using SC-CO2, Chem. Eng. Commun. 201 (2014) 300-322, https://doi.org/10.1080/00986445.2013.768237.

[49] J. Wang, Y. Wang, L. Zheng, S. Ni, Z. Fan, R. Yao, K. Chen, Kinetic study on extraction of red pepper seed oil with supercritical CO2, Chin. J. Chem. Eng. 22 (2014) 44-50, https://doi.org/10.1016/S1004-9541(14)60003-3. 